\title{
Friends' Company Affected My Life: A Case Study
}

\author{
Mafia Shahzadi ${ }^{*}$
}

Silver Lining Hospital, Lahore-Pakistan

\author{
Corresponding author \\ Mafia Shahzadi, Silver Lining Hospital, Lahore-Pakistan. E-mail: mafia. \\ mahak@yahoo.com
}

Submitted:01 June2018; Accepted:07 June 2018; Published: 20 June 2018

\begin{abstract}
Drug addiction leads to lack of control over behavior and compulsion of behavior in taking drugs despite of adverse consequences. The withdrawal symptoms of drug addiction disorder can be managed by medication and various psychological strategies such as Psycho-education, deep breathing, Progressive muscle relaxation (PMR), Positive coping statement, Distraction techniques, motivation enhancement therapy, assertive training, Costbenefit analysis, Relapse prevention, Anger management and12 step program.
\end{abstract}

Keywords: Drug Addiction, Psycho Education, Deep Breathing, Distraction Techniques, Assertive Training, Cost-benefit Analysis

\section{Abbreviations: PMR: Progressive Muscle Relaxation}

\section{Introduction}

Drug addiction is a physical, social and psychological disease which affects an individual's personal and social life while the root of drug addiction is denial $[1,2]$. Additionally, addiction of any substances has pathological relationship with mood and thoughts which become source of mental health problems such as illogical thoughts, negative thoughts and problematic behavior as well [3]. Here, we report a case of Drug Addiction which presented symptoms of Stress, Craving, Muscle's tension, Nail biting, anger and Lack of assertive response. Symptoms of the client were managed by medication and many psychological strategies such as Distraction techniques, assertive training, Cost-benefit analysis, Relapse prevention, Anger management and 12 step program.

\section{Case Report}

The client was a healthy individual without any significant problem in his life. Client reported that he had been a pampered child since his early age. The client's problem started when he was 25 years of age. After completing his graduation he joined a music band as a profession. At that time he was also using cigarettes and used paan. He got indulge in bad company as he joined the musical band. His friends in the band offered him to take alcohol, first time he started taking alcohol at the age of 25 . He mostly took alcohol only when he went to any concert and he took alcohol twice or thrice in a month. He continued this behavior for almost 10 years without any problem. At the age of 27 he got a job in a pharmaceutical company. He performed very well at his occupation. His boss was very happy with him. His salary was 40 thousands at starting. Side by side he was also continued his habit of smoking, rarely used alcohol on occasions like party, eid or any marriage ceremony. But at the age of 28 years when he got significant increase in his salary which was approximately 70 thousands per month he stared to take alcohol on regular basis. He started showing aggression and stubborn behavior. He got relationship problem with his father, mother and his wife because they prohibited him from taking alcohol. After that he was also not able to perform well at his job. After repeated warnings he got fired from his job. Now he was not able to use alcohol. He showed aggressive behavior toward his wife and mother when they refused to give him money which he used for buying alcohol. After that his brother decided to admit him in the hospital. Now, the client had problems of Stress, Craving, Muscle's tension, Nail biting, anger and Lack of assertive response.

Firstly, psychiatric prescribed him medicine for managing his withdrawal symptoms of addiction and others such as Stress, Craving, Muscle's tension, Nail biting, anger and Lack of assertive response. After then he was referred to psychologist for individual sessions. In individual session, Subjective and Objective components of assessment such as: behavioral observation, clinical interview, mental status examination, subjective rating of the problems, trait anger and expression scale, alcohol Smoking and substance involvement screening test (ASSIST) and addiction severity index (ASI) were used.

After assessment, the client's case was formulated. In case formulation, predisposing, precipitating, and maintaining factors were assessed (Figures 1).

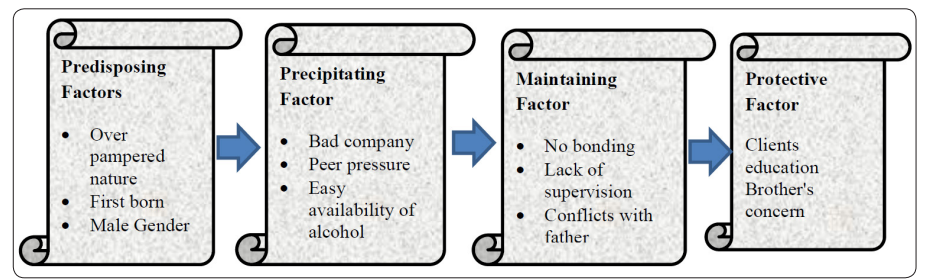

Figure 1: Case Formulation

After this, psychologist understood how his problem started. His family also psycho-educated about his illness. 


\section{Suspected Problem}

According to DSM 5 the client was diagnosed other (or unknown) Substance withdrawal disorder (292.0).

\section{Management}

As the client was educated, the psychologist used the technique of psych-education to tell him that how he developed tolerance on alcohol. In this process, psychologist also psycho-educated the client about the cycle of drug addiction related to any substance.

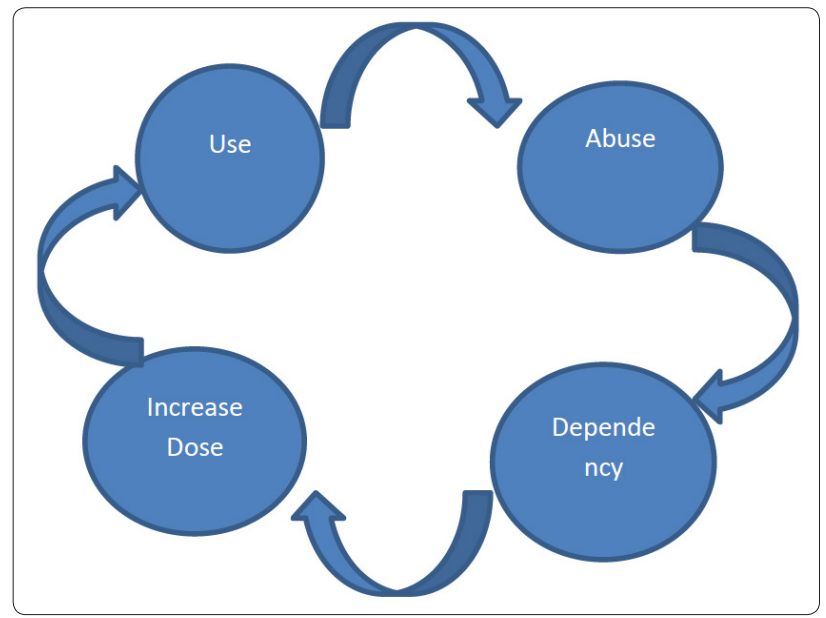

Figure 2: Cycle of Drug Addiction

On the other hand, he was also taught more about process of drug addiction this way such as psychologist told to him that there is positive relationship between antecedent, behavior and consequences.

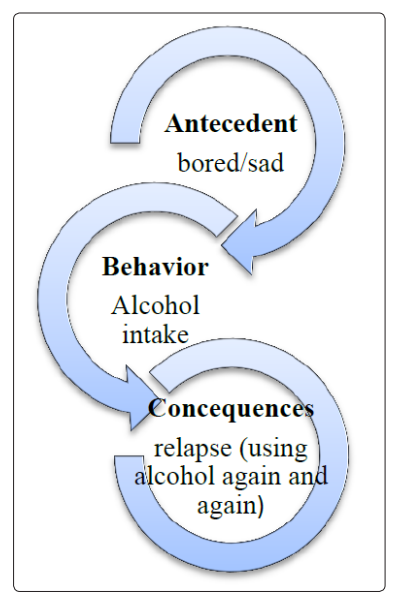

Figure 3

In this case, every symptom of the client was managed separately. Firstly, client remained on medication for 7 days to manage his withdrawal symptoms, next psychological treatment was started. In individual sessions, the client's compulsive behavior was managed by deep breathing, focused muscle relaxation technique, costbenefits analysis, response prevention and 12 step program; Craving was managed by Motivational approaches such as motivational interviewing (MI), motivational enhancement therapy (MET), Lack of assertive response in friend's circle was managed by assertive training during group and individual sessions [5]. His stress and nail biting were managed through positive statements and distractions techniques in physical and mental level and family problems was resolved by family counseling and couple therapy. Lastly, the client's anger was also controlled by anger cycle, ABC model of anger, distraction techniques cognitively and behaviorally and positive coping statements [4].

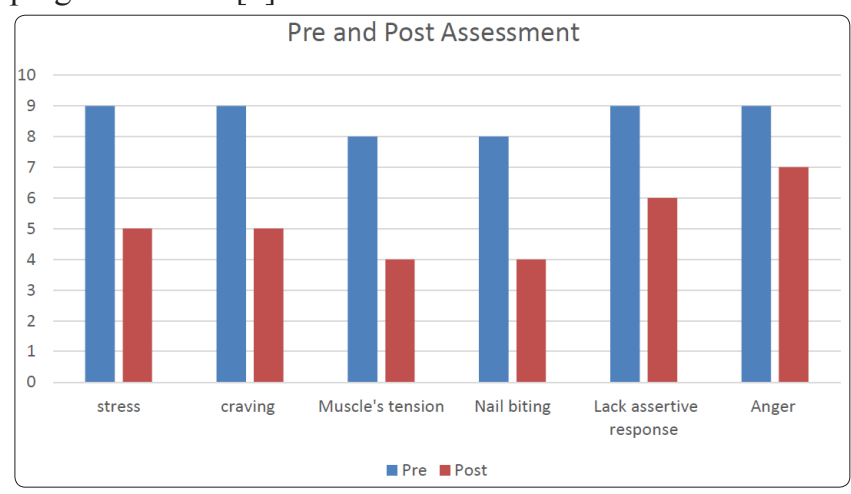

Figure 4: Outcome of Pre and Post Assessment

\section{Discussion}

The history of drugs is old as man himself while numerous researches such as this current research showed that most people experienced cross addiction. Additionally, addiction of any substances has pathological relationship with mood and thoughts which become source of mental health problems such as illogical thoughts, negative thoughts and problematic behavior as well [6]. In this case, the addiction of alcohol affected on his behavior and his relationship also affected with his all family members except with his brother. Furthermore, it is evidence based that drug addiction is a problem of all over the world. Similarly, one research showed that $7 \%$ of people in USA are addicted to various substances such as marijuana and alcohol, after having knowledge about harms of addiction [7]. Similarly, in this current case the client also started alcohol instead of knowing the harmful effect on biologically, psychologically, socially and spiritually as well. Additionally, in the same way, another research supported that the use of drugs become a cause of extreme negative and positive emotions such as happiness, anxiety, sadness and aggressive behavior [8]. Similarly, in this case, the client could not control negative emotions of sadness and anger due to excessive drug use.

\section{Conclusion}

With good rapport building and careful assessment, psychologist can easily help the client to solve his problems with the help of psychologist. In this case, a client came with numerous problems and the root of every problem was related to substances.

\section{References}

1. American Psychiatric Association. (2013) "Diagnostic and Statistical Manual of Mental Disorders, 5th edn. Arlington, VA: American Psychiatric Association."

2. Bolger N, Schilling E A (2005) Personality and the problems of everyday life: the role of neuroticism in exposure and reactivity to daily stressors 59: 355-386.

3. Brown B (2012) Addiction: failure of control over maladaptive incentive habits. Current opinion in neurobiology (CON) 23: 564-572.

4. Chwarts G (2006) Anger Management. The Office Politic. Men's Health magazine. Emmaus, PA: Rodale, Inc.

5. Jacobson E (1938) Progressive relaxation. Chicago: University 
of Chicago Press.

6. Nestler E J (2008) "Review. Transcriptional mechanisms of addiction: role of DeltaFosB". Philos. Trans. R. Soc. Lond., B, Biol. Sci 363: 3245-3255.

7. Robert F (2001) Understanding life: Understanding Unchurched
America. New York: Oxford 158-159.

8. Steiner H, Waes V (2013) "Addiction-related gene regulation: risks of exposure to cognitive enhancers vs. other psycho stimulants". Prog. Neurobiol 100: 60-80.
Copyright: (02018 Mafia Shahzadi. This is an open-access article distributed under the terms of the Creative Commons Attribution License, which permits unrestricted use, distribution, and reproduction in any medium, provided the original author and source are credited. 